\title{
Optimasi Penempatan Exhaust Fan dalam Rumah dengan CFD
}

\author{
Yonatan K. A. Sarumaha ${ }^{1 *}$, Amelia Sugondo ${ }^{2}$ \\ ${ }^{1}$ Program Studi Teknik Mesin, Fakultas Teknologi Industri, Universitas Kristen Petra \\ Jl. Siwalankerto 121-131, Surabaya 60236, Indonesia \\ ${ }^{2}$ Pusat Studi Sustainable Energy, Fakultas Teknologi Industri, Universitas Kristen Petra \\ Jl. Siwalankerto 121-131, Surabaya 60236, Indonesia \\ * Penulis korespondensi; E-mail: amelia@petra.ac.id
}

\begin{abstract}
ABSTRAK
Pengkondisian udara dalam ruangan sangatlah penting. Hal ini dapat mengurangi sick building syndrome (SBS) yang dapat mengganggu aktifitas penghuni. Salah satu cara untuk mengkondisikan udara adalah dengan ventilasi mekanik. Penempatan exhaust fan sebagai ventilasi mekanik guna mendapatkan posisi optimum perlu dikaji. Pengkajian dilakukan dengan melakukan simulasi rumah $12.5 \mathrm{~m}$ x 8.2m menggunakan Autodesk CFD 2019. Simulasi dilakukan pada lima posisi penempatan exhaust fan untuk membandingkan suhu dan kecepatannya pada setiap ruangan. Hasil dari simulasi didapatkan perbedaan suhu udara dan kecepatan udara dari tiap posisi yang diambil pada setiap ruangan dan dibandingkan dengan nenggunakan Metode Tukey. Didapatkan bahwa posisi penempatan exhaust fan tidak berpengaruh signifikan. Exhaust fan dapat diletakkan dimana saja didalam ruangan. Yang perlu menjadi perhatian adalah volume udara yang disirkulasikan dalam ruangan, agar udara segar dapat masuk dan mengurangi SBS.
\end{abstract}

Kata kunci: Optimasi; Penempatan Exhaust Fan; Computational Fluid Dynamic; Sick Building Syndrome; Index Air Quality.

\begin{abstract}
Indoor air conditioning system is very important. This can reduce sick building syndrome (SBS) which can interfere with occupant activities. One of the ways to condition the air is by mechanical ventilation. The placement of the exhaust fan as a mechanical ventilation in order to get the optimum position needs to be studied. The assessment was carried out by simulating a $12.5 \mathrm{~m}$ $x 8.2 m$ house using Autodesk CFD 2019. The simulation was carried out in five positions where the exhaust fan was placed to compare the temperature and speed in each room. The simulation results obtained the difference in air temperature and air velocity from each position taken at each room and compared using Tukey's method. It was found that the position of the exhaust fan placement did not have a significant effect. The exhaust fan can be placed anywhere in the room. What needs to be considered is the volume of air circulated in the room, so that fresh air can enter and reduce SBS.
\end{abstract}

Keywords: Optimation; exhaust fan placement; Computational Fluid Dynamic; Sick Building Syndrome, Index Air Quality.

\section{PENDAHULUAN}

Manusia menghabiskan 80\% waktunya didalam ruangan, entah didalam rumah, atau tempat kerja. Udara di dalam ruangan biasanya lebih berpolusi daripada di luar ruangan akibat emisi di dalam ruangan, serta rendahnya laju pergantian udara [1,2]. Rendahnya laju pergantian udara dapat menyebabkan sick building syndrome (SBS) dimana penghuni mengalami pusing, merasa lelah, iritasi mata, hidung dan tenggorokan, serta kulit kering [3].

Untuk mengurangi SBS, perlu adanya ventilasi untuk pertukaran udara. Terdapat dua jenis ventilasi, yaitu ventilasi natural berdasar perbedaan tekanan udara di luar ruangan dan di dalam ruangan, serta ventilasi mekanik yang menggunakan kincir dengan penggerak motor atau blower [4]. Menurut penelitian yang sudah ada, penggunaan ventilasi natural terbatas pada kecepatan angin di luar rumah, kemudian ventilasi natural juga tidak cocok untuk musim hujan karena tidak mungkin membuka jendela saat hujan dan kotoran akan masuk ke rumah. Sementara itu, penggunaan ventilasi mekanik juga meningkatkan penggunaan energi, serta udara kotor lebih mudah masuk ke dalam rumah [5].

Suhu udara yang nyaman bagi manusia adalah relatif bagi tiap orang. Faktor yang mempengaruhi 
kenyamanan adalah metabolisme tubuh, insulasi pakaian, suhu udara, radiant temperature, kecepatan udara dan kelembaban. Metabolisme dan insulasi tergantung dari masing-masing orang, sedangkan empat faktor lainnya disebabkan karena lingkungan. Sensasi nyaman muncul dari pikiran setiap orang, sehingga rasa nyaman dapat berbeda antara satu dengan yang lainnya. Suatu kondisi dikatakan nyaman bila $80 \%$ orang dalam suatu kondisi tersebut mengatakan nyaman [6]. Berdasarkan penelitian dari H. Feriadi et. all, suhu udara normal orang Indonesia adalah $29.2^{\circ} \mathrm{C}$, dengan preferensi nyaman dibawah $29.2^{\circ} \mathrm{C}$ hingga $26^{\circ} \mathrm{C}$ [7].

Beberapa penelitian tentang penggunaan hybrid ventilation (ventilasi mekanik dan natural) pernah dilakukan $[5,8]$. Hasilnya menunjukkan efektifitas ventilasi bergantung dari posisi rumah dan lingkungan sekitar.

Pada penelitian ini, disimulasikan lima lokasi penempatan exhaust fan dalam ruangan guna melihat efektivitas kerja exhaust fan dengan membandingkan suhu dan kecepatan udara dalam ruang tamu, kamar tidur utama, kamar tidur kedua, dapur, dan kamar mandi pada rumah $12.5 \mathrm{~m} \times 8.2 \mathrm{~m}$.

\section{METODE YANG DIGUNAKAN}

Simulasi dilakukan menggunakan Autodesk CFD 2019 versi Student License dengan metode Turbulen RNG (renormalization group). Dalam rumah terdapat sumber panas kompor sebesar $700 \mathrm{~W}$, dan terdapat satu orang pada tiap ruangan dengan heat generation masing-masing orang $60 \mathrm{~W}$. Suhu udara luar sebesar $30^{\circ} \mathrm{C}$.

Rumah yang digunakan berukuran $12.5 \mathrm{~m} \times 8.2 \mathrm{~m}$ dengan tinggi $3 \mathrm{~m}$ seperi pada Gambar 1, dengan penempatan exhaust fan pada plafon seperti pada Gambar 2. Exhaust fan yang dipasang merupakan model ceiling fan, dengan besar flow rate pembuangan udara pada tiap ruangan yang dapat dilihat pada Tabel 1 dengan merujuk pada ANSI/ASHRAE Standart 62.1-2016 [4].

Tabel 1. Flow rate pembuangan udara yang dibutuhkan ruangan

\begin{tabular}{lc}
\hline \multicolumn{1}{c}{ Ruangan } & Flow Rate $(\mathrm{L} / \mathrm{s})$ \\
\hline Ruang Tamu & 11.75 \\
Kamar Tidur Utama & 9.05 \\
Kamar Tidur Kedua & 8.15 \\
Kamar Mandi & 12.5 \\
Dapur & 30 \\
\hline
\end{tabular}

Terdapat lima posisi penempatan exhaust fan, yang ditunjukkan dengan angka 1-5, dan huruf A-E sebagai penanda ruangan. Sebagai contoh, penempatan exhaust fan A1 yang berarti di dapur pada posisi center. Tabel 2 menunjukkan penomoran exhaust fan pada Gambar 2. Exhaust fan yang berada pada ujung ruangan dipasang dengan jarak $35 \mathrm{~cm}$ dari tembok.
Tabel 2. Penomoran exhaust fan pada Gambar 2

\begin{tabular}{lccc}
\hline \multicolumn{1}{c}{ Ruangan } & Huruf & Posisi exhaust fan Angka \\
\hline Kamar Tidur Utama & A & Center & 1 \\
Dapur & B & Kanan Atas & 2 \\
Kamar Mandi & C & Kanan Bawah & 3 \\
Kamar Tidur Kedua & D & Kiri Atas & 4 \\
Ruang Tamu & E & Kiri Bawah & 5 \\
\hline
\end{tabular}

Kamar tidur kedua, dapur dan ruang tamu memiliki ventilasi dimana memungkinkan masuknya udara dari luar. Besar luasan ventilasi dapat dilihat pada Tabel 3. Ventilasi ini diberi boundary condition $\mathrm{P}_{\text {gauge }}=0 \mathrm{~atm}$, dan suhu $30^{\circ} \mathrm{C}$. Di setiap ruangan juga terdapat lubang yang memungkinkan udara bergerak dari satu ruangan ke ruang lainnya dengan luas $0.08 \mathrm{~m}^{2}$.

Tabel 3. Luasan ventilasi pada tiap ruangan

\begin{tabular}{lc}
\hline \multicolumn{1}{c}{ Ruangan } & Luas $\left(\mathrm{m}^{2}\right)$ \\
\hline Dapur & 0.43 \\
Ruang tamu & 0.16 \\
Kamar tidur kedua & 0.08 \\
\hline
\end{tabular}

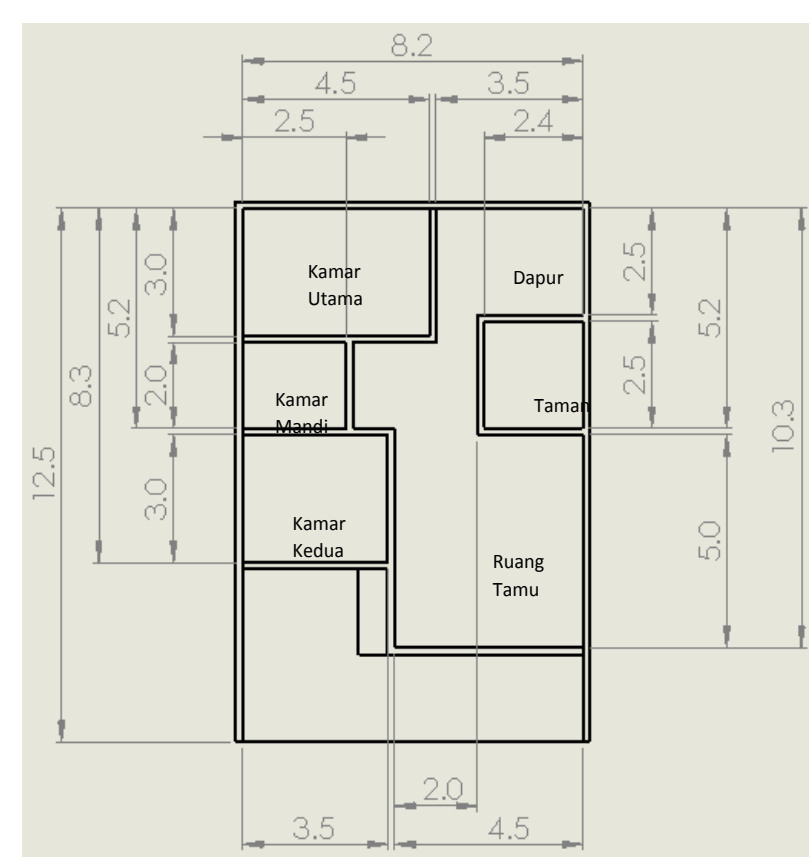

Gambar 1. Desain rumah (satuan dalam meter).

Setiap ruangan akan disimulasikan lima penempatan exhaust fan yaitu: center, kanan atas, kanan bawah, kiri atas dan kiri bawah. Hasil yang diambil dari setiap simulasi adalah kecepatan udara dan suhu dengan membuat bidang mendatar pada $1 / 2$ dari tinggi total ruangan. Garis A-B, B-C, C-D pada Gambar 3 merupakan lokasi pengambilan data kecepatan udara dan suhu. Satu garis menghasilkan delapan titik pengambilan data suhu dan kecepatan udara. Lingkaran merah di setiap ruangan menandakan penempatan orang di setiap ruangan. Data diambil pada lima posisi penempatan exhaust fan di setiap ruangan dan dibandingkan menggunakan aplikasi Minitab dengan metode Tukey pair ways. 


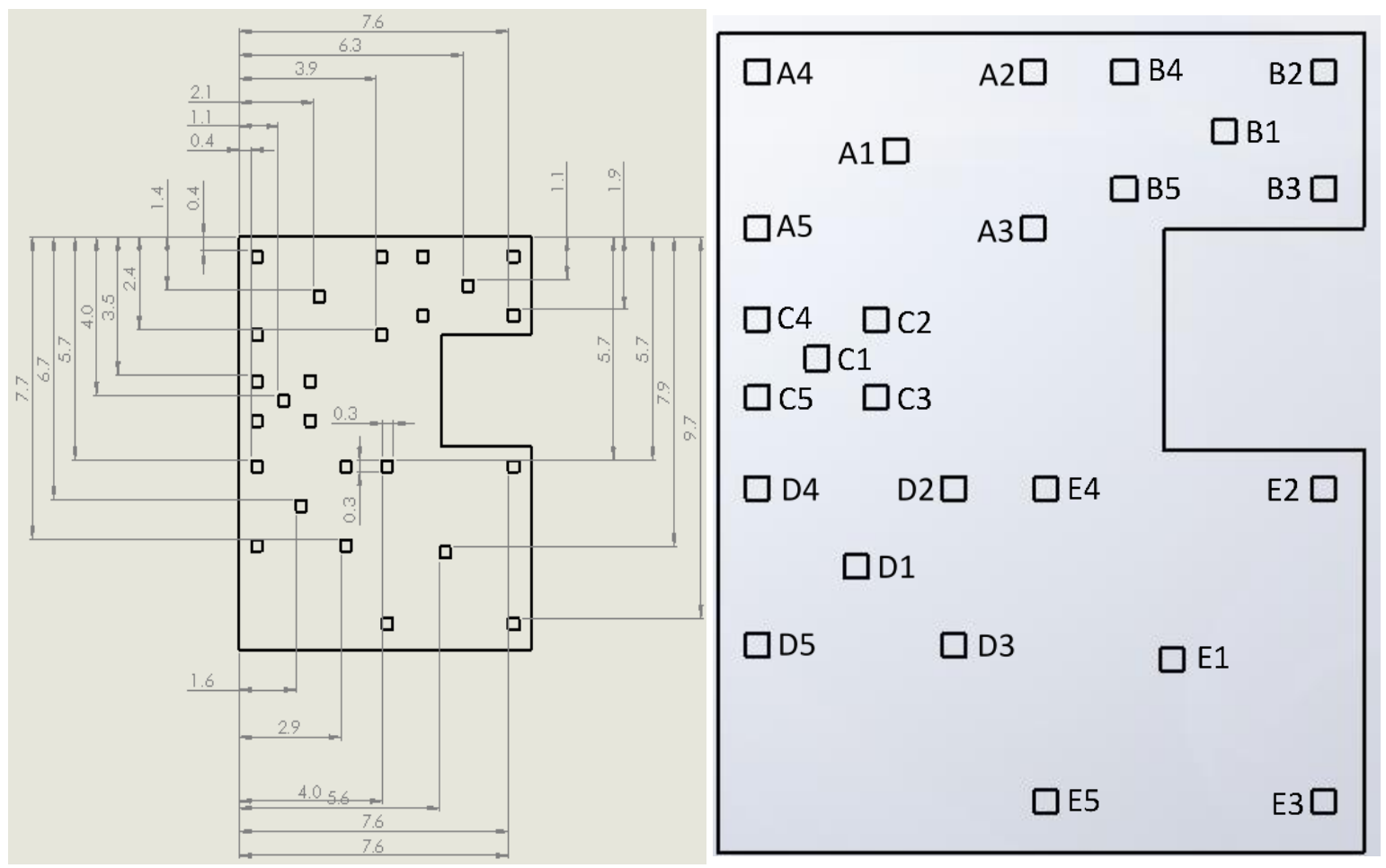

Gambar 2. Posisi ventilasi pada plafon rumah (satuan dalam meter).

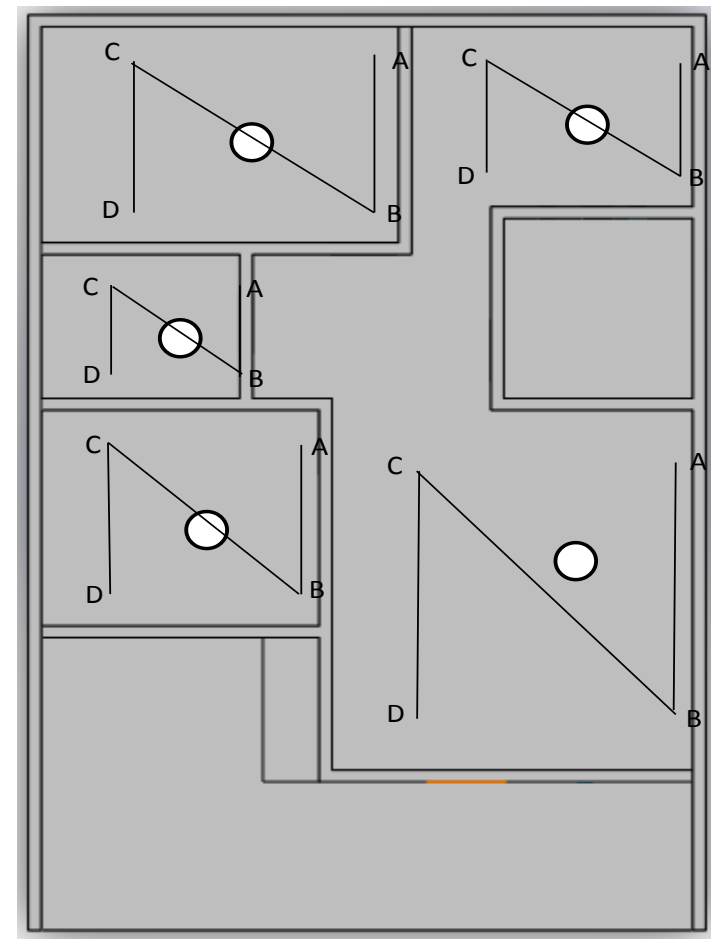

Gambar 3. Daerah pengambilan data kecepatan udara dan suhu

\section{HASIL DAN PEMBAHASAN}

Pengambilan data dilakukan pada breathing zone sesuai dengan yang telah diatur dalam ANSI/ ASHRAE Standart 62.1-2016, yaitu pada daerah antara $75 \mathrm{~mm}-1800 \mathrm{~mm}$ dari lantai, dan lebih dari $600 \mathrm{~mm}$ dari tembok [4]. Gambar 4 menunjukkan grafik kecepatan udara dari setiap ruangan dan
Gambar 5 menunjukkan grafik suhu dari setiap ruangan. Data diambil mengacu pada Gambar 3, dengan parametric distance yang merupakan sumbu $\mathrm{x}$ dari grafik menunjukkan jarak dari titik A hingga D di setiap ruangan. Terlihat pada grafik suhu, tedapat lonjakan suhu di dapur, kamar mandi dan kamar tidur kedua. Lonjakan suhu tersebut adalah suhu orang yang terdapat di dalam ruangan. Hal ini 
dibuktikan dengan terdapat kecepatan udara sebesar $0 \mathrm{~cm} / \mathrm{s}$ yang menandakan data yang diambil pada titik dimana terdapat orang di ruangan. Sedangkan pada kamar tidur utama, dan ruang tamu tidak terdapat lonjakan suhu seperti pada ruangan lain karena suhu yang tercatat adalah suhu disekitar orang, bukan suhu badan orang tersebut. Hal ini dapat dibuktikan dengan tidak adanya kecepatan udara sebesar $0 \mathrm{~cm} / \mathrm{s}$.

Gambar 6 merupakan rata-rata kecepatan udara di setiap ruangan dengan lima posisi penempatan exhaust fan. Di dapur dan kamar tidur utama penempatan exhaust fan di tengah menghasilkan rata-rata kecepatan udara yang terbesar yaitu $9.29 \mathrm{~cm} / \mathrm{s}$ dan $2.77 \mathrm{~cm} / \mathrm{s}$. Pada kamar mandi, penempatan exhaust fan pada kanan atas menghasilkan kecepatan udara terbesar sebesar $2.67 \mathrm{~cm} / \mathrm{s}$. Penempatan exhaust fan pada bagian kiri bawah menghasilkan kecepatan udara terbesar pada kamar tidur kedua dengan kecepatan udaranya sebesar $3.98 \mathrm{~cm} / \mathrm{s}$. Sedangkan pada ruang tamu, kecepatan udara sebesar $3.63 \mathrm{~cm} / \mathrm{s}$ menjadi yang terbesar dengan penempatan exhaust fan pada kanan bawah. Dapur memiliki kecepatan udara rata-rata terbesar dibandingkan di ruangan lain. Hal ini diakibatkan oleh terdapat lubang ventilasi yang lebih besar daripada ruangan lainnya. Ruang tamu juga memiliki rata-rata kecepatan udara tertinggi kedua, karena terdapat ventilasi yang lebih besar daripada kamar tidur kedua.
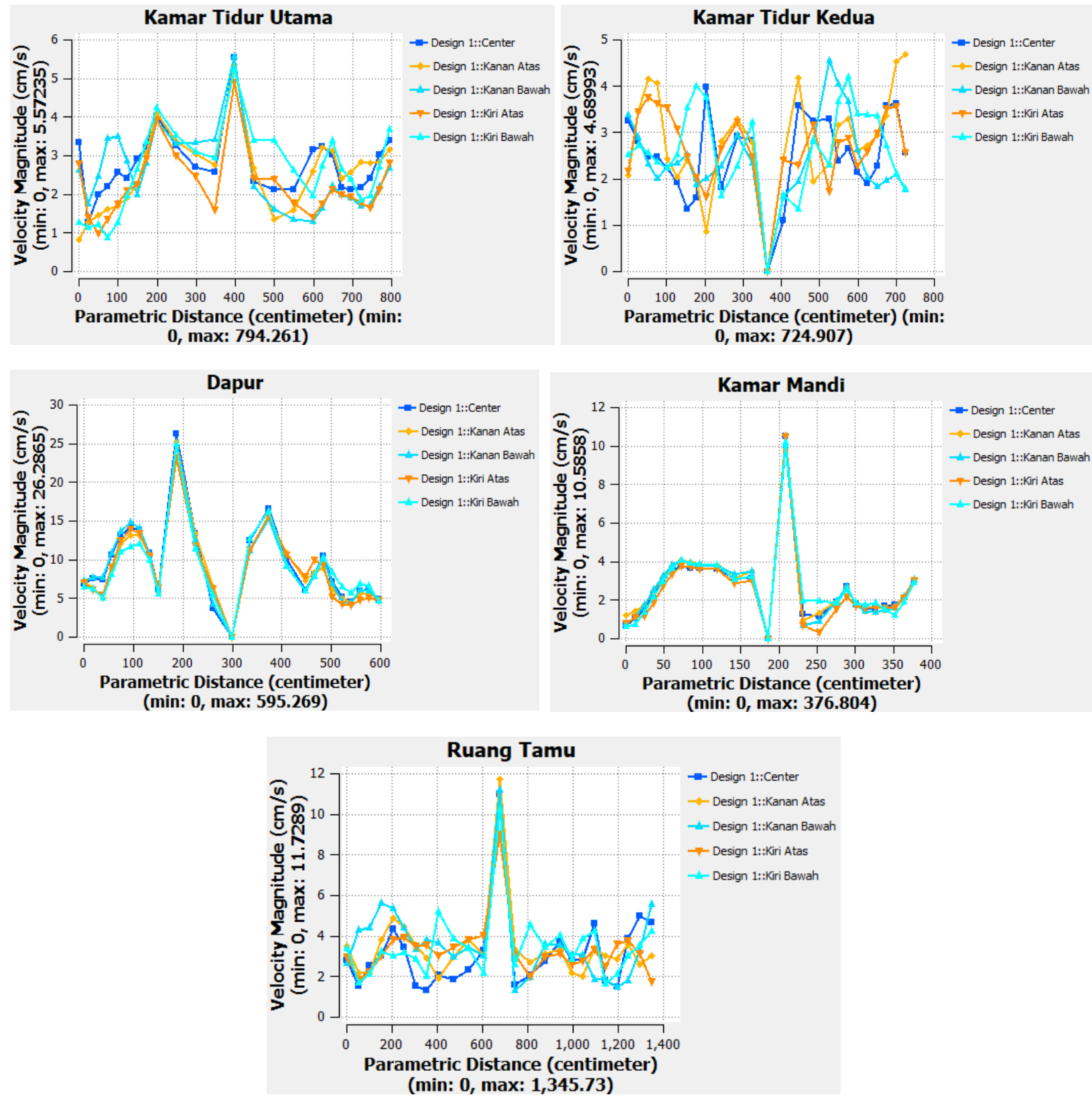

Gambar 4. Grafik kecepatan udara pada setiap ruangan 

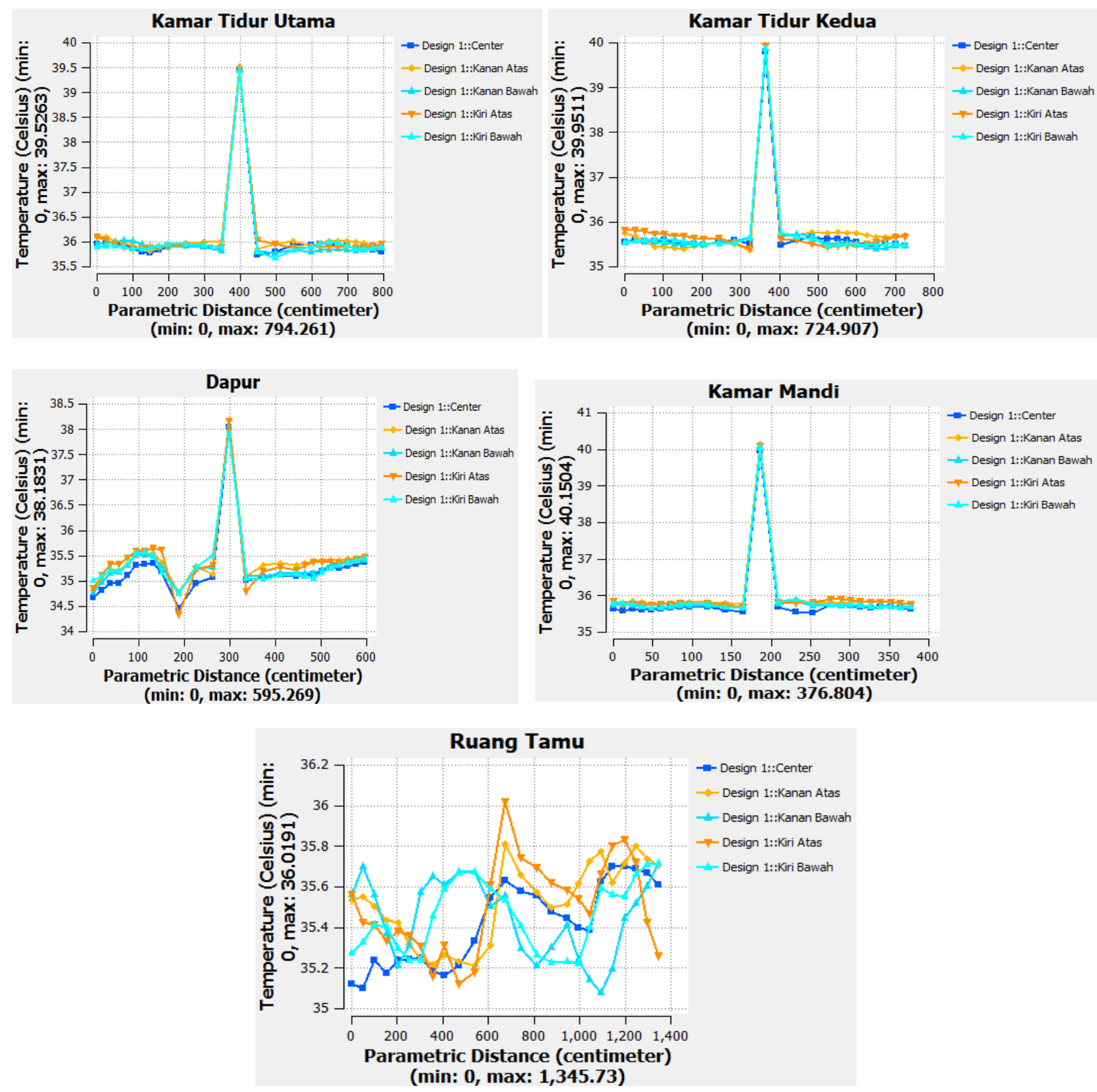

Gambar 5. Grafik suhu pada tiap ruangan

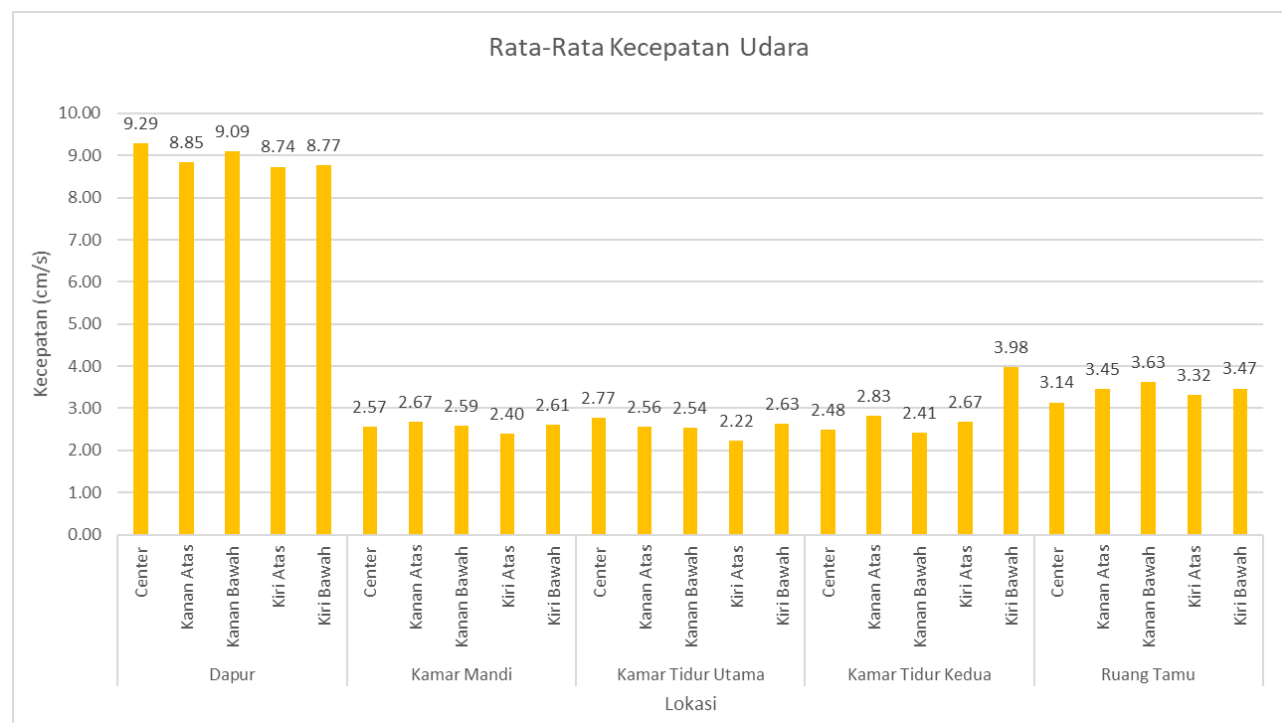

Gambar 6. Grafik rata-rata kecepatan udara pada tiap ruangan 
Bila dibandingkan dengan metode statistik Tukey dengan tingkat keyakinan 95\%, tidak terdapat perbedaan kecepatan yang signifikan dari lima posisi penempatan exhaust fan di setiap ruangan. Hal ini dapat dilihat pada Gambar 7, dimana posisi penempatan exhaust fan di setiap ruangan berada pada satu grouping.

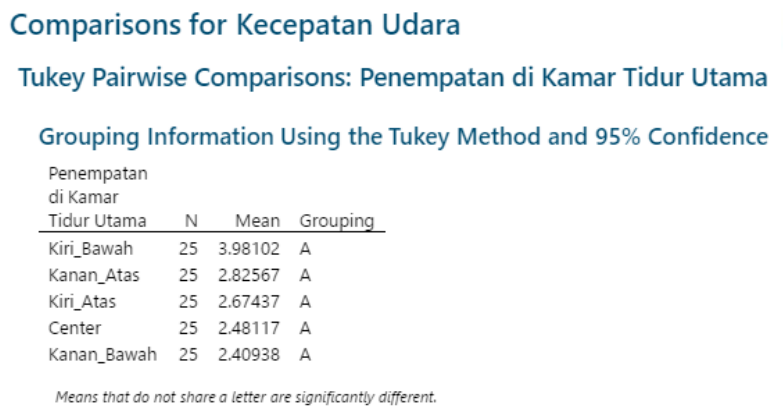

\section{Comparisons for Kecepatan Udara}

Tukey Pairwise Comparisons: Penempatan di Dapur

Grouping Information Using the Tukey Method and $95 \%$ Confidence

\section{Perempatan}

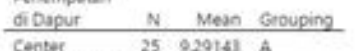

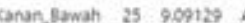

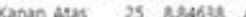

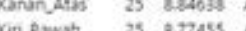

kiriatas 25 a.73520 A

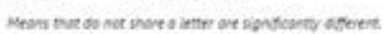

Gambar 8 menunjukkan rata-rata suhu udara pada tiap ruangan. Penempatan exhaust fan ditengah mengakibatkan suhu ruangan terendah pada dapur sebesar $35.22^{\circ} \mathrm{C}$, kamar mandi sebesar $35.82^{\circ} \mathrm{C}$, dan ruang tamu sebesar $35.41^{\circ} \mathrm{C}$. Kamar tidur utama memiliki rata-rata suhu terendah bila exhaust dipasang pada kiri bawah, kanan bawah atau tengah

\section{Comparisons for Kecepatan Udara}

Tukey Pairwise Comparisons: Penempatan di Kamar Tidur Kedua

Grouping Information Using the Tukey Method and $95 \%$ Confidence Penempatan

o kama

Tidur Kedtus N Mean Grouging

$\begin{array}{llll}25 & 398102 & A \\ \text { Gananstan } & 25 & 282567\end{array}$

Kin_atas $25 \quad 267437$.

Cecter as atablo a

cangn Bswah 25 200938. A

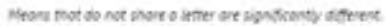

\section{Comparisons for Kecepatan Udara}

Tukey Pairwise Comparisons: Penempatan di Kamar Mandi

Grouping Information Using the Tukey Method and $95 \%$ Confidence Penemputan di

\begin{tabular}{|c|c|c|c|}
\hline Samars & $N$ & Mean & Grouping \\
\hline Karan_Atas & 25 & 2.67140 & $a$ \\
\hline Nit, Bawah & 25 & 2.81143 & A \\
\hline canan \&awah & 25 & 250160 & $A$ \\
\hline center & 25 & 2.56772 & $A$ \\
\hline Xin atas & 25 & 240906 & $A$ \\
\hline
\end{tabular}

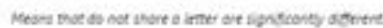

\section{Comparisons for Kecepatan Udara}

Tukey Pairwise Comparisons: Penempatan di Ruang Tamu

Grouping Information Using the Tukey Method and $95 \%$ Confidence

\begin{tabular}{llrl}
$\begin{array}{l}\text { Aenempatan di } \\
\text { Ruang Tamu }\end{array}$ & N & Mean Grouping \\
\hline Kanan_Bawah & 25 & 3.62853 & A \\
Kin_tawah & 25 & 3.46823 & A \\
Kanan_atas & 25 & 3.45000 & A \\
KiruAtas & 25 & 3.31852 & A \\
Center & 25 & 3.13693 & A
\end{tabular}

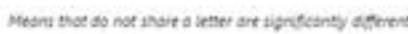

Gambar 7. Perbandingan Tukey untuk kecepatan udara pada setiap ruangan

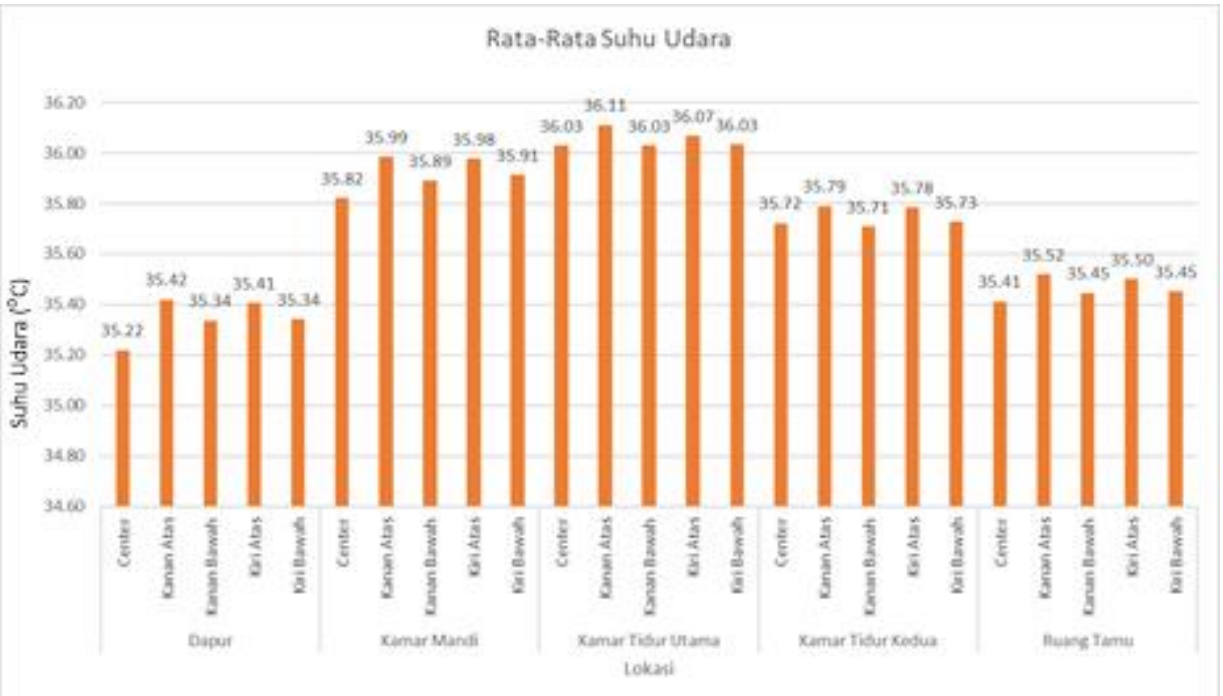

Gambar 8. Grafik rata-rata suhu pada setiap ruangan 
ruangan. Penempatan ini menyebabkan suhu ruang meningkat menjadi $36.03^{\circ} \mathrm{C}$. Pada kamar tidur kedua suhu terendah didapat bila memasang exhaust pada kanan bawah ruangan dengan suhu sebesar $35.71^{\circ} \mathrm{C}$. Suhu di kamar tidur utama dan kamar mandi relatif lebih tinggi daripada ruangan lainnya. Hal ini disebabkan oleh tidak adanya ventilasi yang memungkinkan udara luar masuk ke ruangan, sehingga suhunya lebih tinggi dari lainnya.

Bila dibandingkan dengan metode statistic Tukey dengan tingkat keyakinan 95\%, tidak terdapat perbedaan yang signifikan dari kelima posisi penempatan exhaust fan terhadap suhu pada ruang. Hasil perbandingan dapat dilihat pada Gambar 9, dimana setiap posisi penempatan exhaust fan pada tiap ruangan terdapat dalam satu grouping.

\section{KESIMPULAN}

Dari hasil simulasi dan dibandingkan datanya dengan metode Tukey, dapat disimpulkan bahwa posisi penempatan exhaust fan tidak berdampak

\section{Comparisons for Suhu Udara \\ Tukey Pairwise Comparisons: Penempatan di Kamar Tidur Utama \\ Grouping Information Using the Tukey Method and $95 \%$ Confidence Penerrostan \\ ti Kamar \\ Tidur Utama N Mean Grouping. \\ Cananfatas 25 35.7901 a

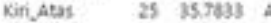 \\ Kintluwah 25 157278 A \\ Center 25 35.7221 A \\ Kanan_Eawah $25 \quad 35,7100$ A

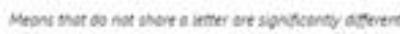

Comparisons for Suhu Udara

Tukey Pairwise Comparisons: Penempatan di Dapur

Grouping Information Using the Tukey Method and $95 \%$ Confidence

Denempstan

didaput N Mean Grouping.

Kanan_Atas 25 35.4195 A

Xoriatas $\quad 25 \quad 35.4057$ A

Xingawiah $25 \quad 15.3434$ a

Kanan_Bawah 25 353365 A

Center 25 352194 A

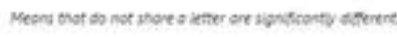

signifikan pada suhu udara dan kecepatan udara di dalam suatu ruangan.

Untuk mendapatkan suhu udara dan kecepatan udara yang baik, perlu adanya ventilasi yang cukup berupa jendela dan lubang angin agar terjadi pertukaran udara dari luar ke dalam sehingga menurunkan suhu dan meningkatkan kecepatan udara dalam ruangan.

Kedepan, dapat diuji dengan membuat ruangan asli agar dapat membandingkan data real dan simulasi. Dapat juga membandingkan data ventilasi natural dan ventilasi mekanik, untuk melihat biaya operasional exhaust fan, serta dikombinasi dengan pendingin ruangan.

\section{DAFTAR PUSTAKA}

[1] Y. Sun, J. Hou, R. Cheng, Y. Sheng, X. Zhang, J. Sundell, 2019, "Indoor air quality, ventilation and their associations with sick building syndrome in Chinese homes", Energy and Buildings, 197:112-119.

\section{Comparisons for Suhu Udara}

Tukey Pairwise Comparisons: Penempatan di Kamar Tidur Kedua

Grouping Information Using the Tukey Method and $95 \%$ Confidence Penempatan

dikamar

Tidur Kedua N Mean Grouping

Kanan_Atas $25 \quad 35.7901$ A

Kinjatas $25 \quad 35.7833$ A

Kiri_Bawah $25 \quad 35.7278$ A

Center $25 \quad 357221$ A

Kanangawah 25 35.7100 A

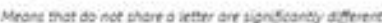

\section{Comparisons for Suhu Udara}

Tukey Pairwise Comparisons: Penempatan di Kamar Mandi

Grouping Information Using the Tukey Method and $95 \%$ Confidence Penempatan di

\begin{tabular}{llll} 
Kamar Mand & N & Mean Grouging \\
\hline Kanac_Atas & 25 & 35.9859 & A \\
Kin_Atas & 25 & 35.9774 & A \\
Kin_Bawah & 25 & 35.9124 & A \\
Kanan_lawah & 25 & 35.9816 & A \\
Center & 25 & 35.2217 & A
\end{tabular}

\section{Comparisons for Suhu Udara}

\section{Tukey Pairwise Comparisons: Penempatan di Ruang Tamu}

\section{Grouping Information Using the Tukey Method and $95 \%$ Confidence}

\begin{tabular}{llrl}
$\begin{array}{l}\text { Aenempatan di } \\
\text { Ruang Tamu }\end{array}$ & N Mean Gequpine \\
\hline Kanan_Atar & 25 & 35.5204 & A \\
Kin_Atas & 25 & 35.5020 & A \\
Kin_Bawah & 25 & 35.4500 & A \\
Kanan_Bawah & 25 & 35.4462 & A \\
Center & 25 & 35.4119 & A
\end{tabular}

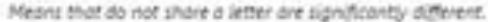

Gambar 9. Perbandingan Tukey untuk suhu udara pada setiap ruangan 
[2] R. Kishi, R.M. Ketema, Y.A. Bamai, A. Araki, T. Kawai, T. Tsuboi, L. Saito, E. Yoshioka, T. Saito, 2018, "Indoor environmental pollutants and their association with sick house syndrome among adults and children in elementary school", Building and Environment, 136: 293301.

[3] A. Norhidayah, L. Chia-Kuang, M.K. Azhar, S. Nurulwahida, 2013, "Indoor air quality and sick building syndrome in three selected buildings", Procedia Engineering, 53:93-98.

[4] ANSI. Standard 62.1, 2016, "Ventilation for acceptable indoor air quality", America: ANSI.
[5] F. Xiuzhang, W. Dingxin, 20115, "Comparison of the efficiency of building hybrid ventilation systems", Energy Procedia, 78:2820-2825.

[6] ANSI. Standard 55, 2017, "The Enviromental Conditions for Human Occupancy", America: ANSI.

[7] H. Feriady, N. H. Wong, 2004, "Thermal comfort for naturally ventilated houses in Indonesia", Energy and Buildings, 36:614-626.

[8] B. Daria, D. Sovetnikov, D. Semashkina, A. Borodinecs, 2017, "Correlation of energy efficiency and thermal comfort depending on the ventilation strategy", Elsevier. Procedia Engineering, 205:503-510. 